\title{
ANÁLISE BIOMECÂNICA DO SALTO TRIPLO INTRODUÇÃO AOS PRINCÍPIOS FUNDAMENTAIS DA INVESTIGAÇÃO E ANÁLISE DO MOVIMENTO ESPORTIVO*
}

\author{
Alberto Carlos Amadio ${ }^{\star \star}$
}

Através do presente trabalino procura-se desenvolver uma análise biomecânica do salto triplo, discutindo-se aspectos relacionados à complexa investigação do movimento esportivo. Baseando-se em estudos experimentais, foram desenvolvidos e aplicados os principais métodos de investigação da biomecânica nas suas áreas básicas de estudo: Cinemática, Dinâmica, Antropometria e Eletromiografia.

A validação dos resultados das mensurações em situações de Laboratório e Treinamento. confrontados com os resultados de Competição, foi feita através do controle das situaçōes, no que diz respeito à população estudada, para as três diferentes mensurações: nivel do rendimento apresentado, controle do êrro dos procedimentos de medida $e$ análise estatística dos parâmetros medidos.

Através da investigação biomecânica procurou-se determinar os parâmetros que influenciam o rendimento no salto triplo. 0 diagnóstico do rendimento foi feito em situação de treinamento, situação de competição e através de mensuração em laboratório

onde realizou-se a simulação do movimento estudado.

A ilustração que segue mostra o organograma da situação experimental da mensuração realizada em treinamento (veja-se $\mathrm{Fi}$ gura 01).

A análise do movimento para o estudo dos parâmetros biomecânicos do complexo da técnica do salto envolveu os seguintes procedimentos de mensuraçāo:

Cinematográfico: análise fotogamétrica com câmeras de alta frequência por mensuração bidimensional. Em tal procedimento partimos do princípio que o movimento estudado, na presente análise, tem uma concepção planar. Já para análises de sobrecarga articular foram empregados procedimentos cinematográficos bidimensionais e tridimensionais.

Dinamométrico: análise da força reação do solo através do uso de plataformas de força, permitindo a representaçāo do vetor força nos três eixos ortoyonais medidos. Foram realizadas análises conseqüentes da sobrecarga de reação articular, por meio de modelos físico-matemáticos que permitiram o cálculo do momento da força muscular nas articulações do segmento perna, momento de inércia, força articular bem como força atuante nos tendões e ligamentos do pé.

-Antropométrico: análise e cálculos por meio de modelos matemáticos experimentais que permitiram a utilização da geometria da massa corporal para a determinação do centro de gravidade, momento de inércia e centro de gravidade das partes do corpo.

Eletromiográfico: análise do potencial de ação muscular através de interpretação dos sinais de Eletromiograma (EMG), identificando-se de forma qualitativa e quantitativa os grupos musculares ativos nas diferentes fases de apoio do salto e seu mecanismo de coordenação muscular.

"Condensado da Tese de Doutoramento, DSHS-Koeln, 1985.

** Professor Assistente Doutor da disciplina de Cinesiologia da EEF-USP. 


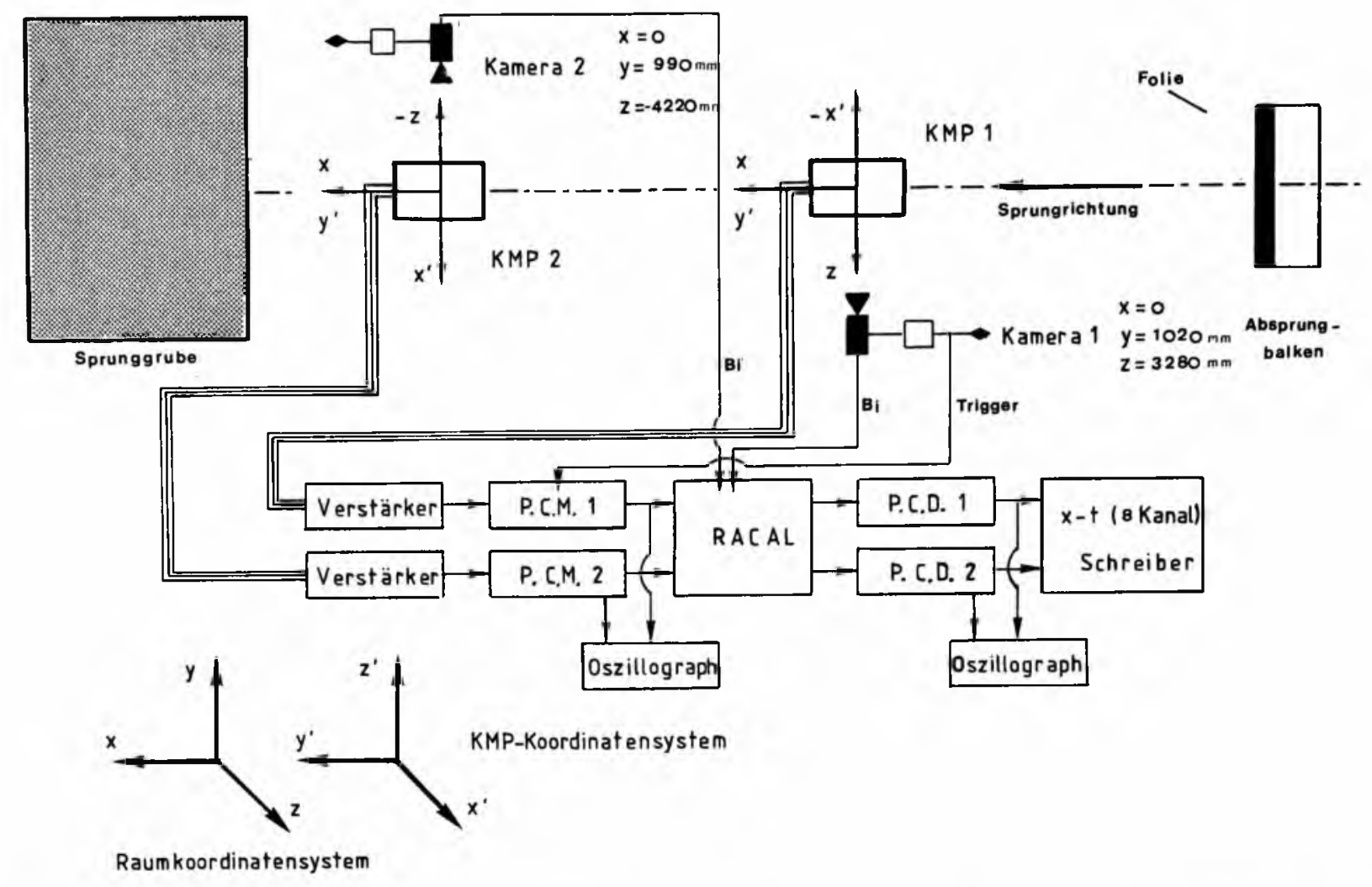

Figura 01: Representação esquemática do organograma experimental da mensuração (KMP: Plataforma de força, PCM: Modulação e codificação dos sinais, PCD: Demodulação e decodificação dos sinais, RACAL: Banda magnética para registro dos dados, Bi: Impulso da câmera).

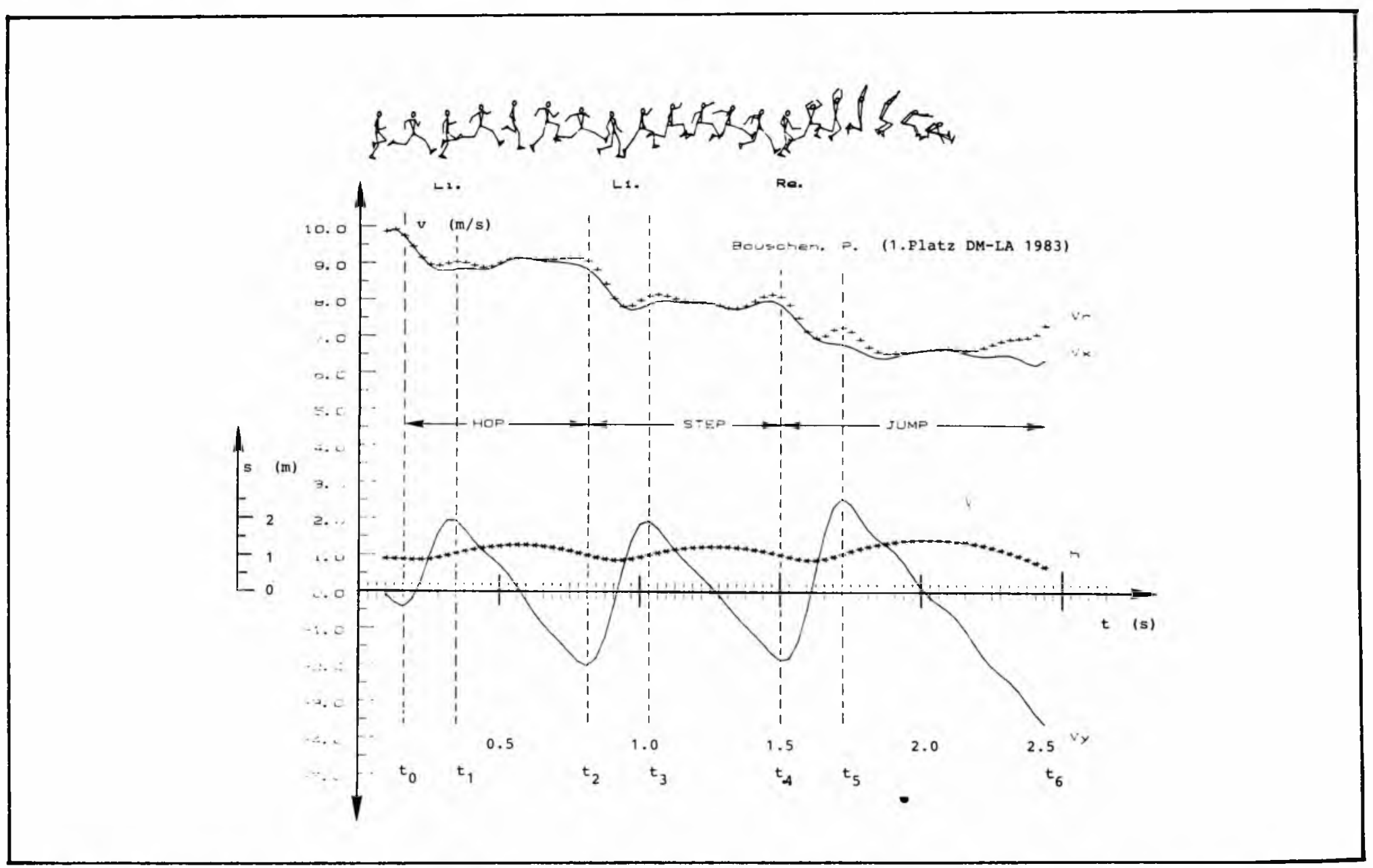

Figura 02: Curvas da velocidade e trajetória do centro de gravidade em função de tempo para P.Bouschen $(17.33 \mathrm{~m})$, representados ao lado do cinegrama do respectivo salto. 
Fundamentando-se nos resultados desta complexa análise biomecânica definimos parâmetros de rendimento das diferentes técnicas de salto, que são trabalhadas visando sua aplicação na prática esportiva. A análise ocupou-se de detalhada descrição dos parâmetros cinemáticos do rendimento para três grupos definidos bem como de três diferentes situaçōes de mensuração: Competição, Treinamento e Simulação do salto.

Através da Figura 02 representa-se graficamente os valores de parâmetros cinemáticos calculados para velocidade: horizontal $\left(v_{x}\right)$, vertical $\left(v_{y}\right)$ e resultante $\left(v_{r}\right)$, bem como para o deslocamento altura ( $h$ ) do centro de gravidade; observados ao lado do cinegrama do salto para o estudo exemplar de um caso.

Além das informaçōes da cinemática durante as fases de apoio e aérea do salto necessitase, para a descrição do movimento, de conhecimentos sobre a força que age em cada uma das fases de apoio.

A amplitude do primeiro pico da força vertical mostra valores extremamente altos para as três fases de apoio do salto, especialmente para o Step (2- apoio) 10.1 kN 15.9 kN, em comparação com $8.7 \mathrm{kN} 11.2 \mathrm{kN}$ para o Hop e o Jump (1ㅇ e $3^{\circ}$ apoios respectivamente) valores estes que até o momento ainda não tinham sido registrados na literatura da prática esportiva. A Figura 03 repre- senta os valores da força reação do solo (vertical $e$ horizontal) para cada uma das fases de apoio do salto triplo de forma exemplar neste estudo da dinâmica do salto.

Os resultados obtidos, referentes a sobrecarga articular, baseiam-se em cálculos efetuados no plano sagital com dados medidos na cinemática e dinâmica da fase de apoio do salto. Desta forma interpretou-se o momento da força muscular, a força de reação articular bem como a força que age no tendão de Aquiles para a articulação superior do tornozelo (talo-crural) e para a articulação femuro-tibial.

Os valores para o momento da força muscular mostraram-se, para a articulação femuro-tibial, maiores que para a articulação superior do tornozelo (talo-crural) nas três fases de apoio. Em relação à força de reação articular, obtivemos, da mesma forma, valores extremamente elevados e registrados com pouca frequência em movimerins esportivos especialmente para Step (2ㅇ apc.u, na articulação superior do tornozelo (talocrural) $18.0 \mathrm{kN}$, assim como para Hop (1ㅇaㅇ apoio) na articı'lação femuro-tibial $18.0 \mathrm{kN}$. A curva da forr. In tendão de Aquiles mostrou valores médi s am torno de $11.5 \mathrm{kN}$ para Step. Os resultados di mensuraçōes no laboratório simulação do sálto e treinamento foram comparados com os resultados de competição para efeito de interpreta-
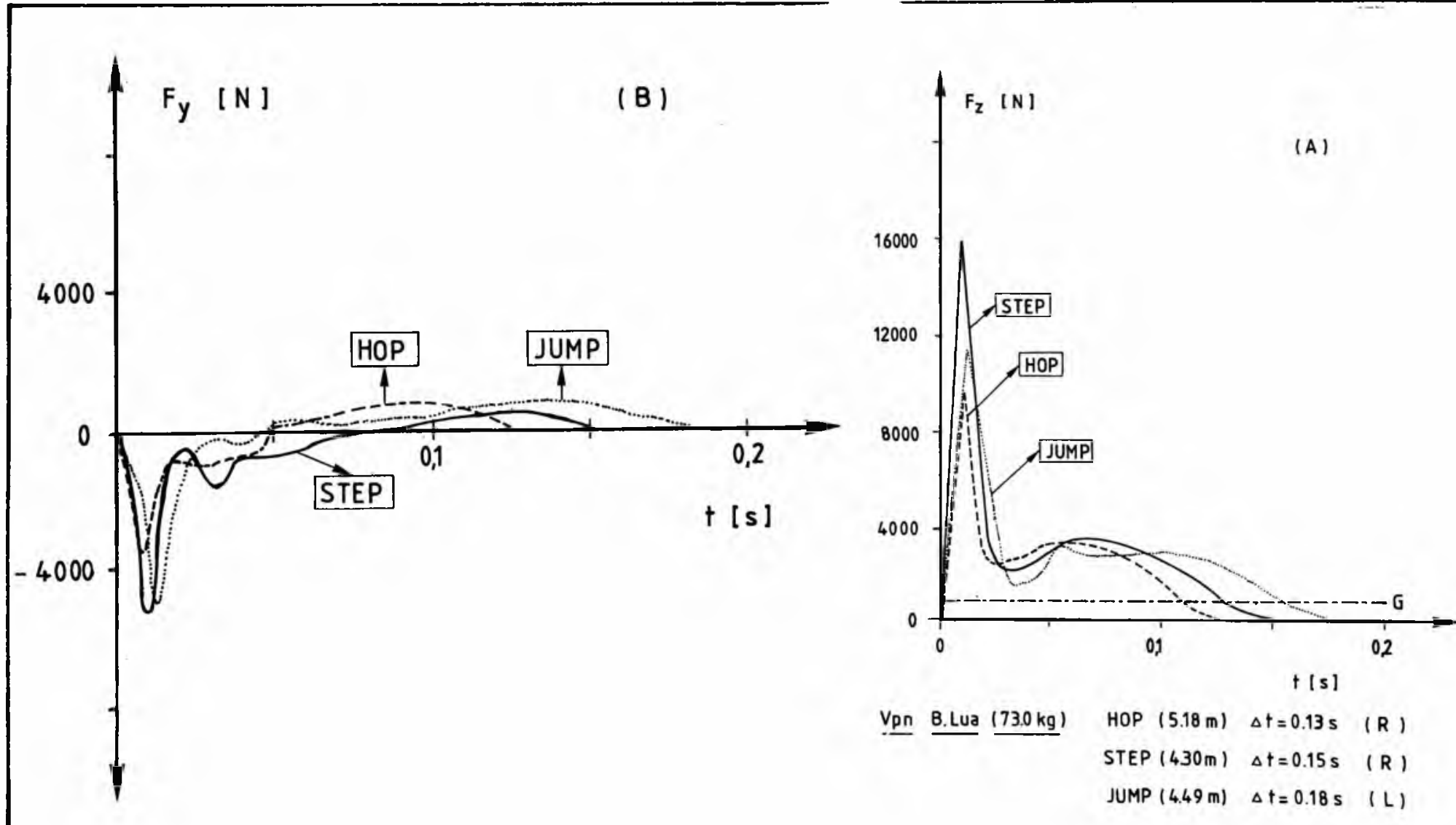

Figura 03: Curvas da Força reação do solo durante as três fases de apoio do salto triplo para B.Lua $(13.97 \mathrm{~m})$. (A): Força vertical $F_{Z},(B)$ : Força horizontal - sentido do salto $F_{y}$. 


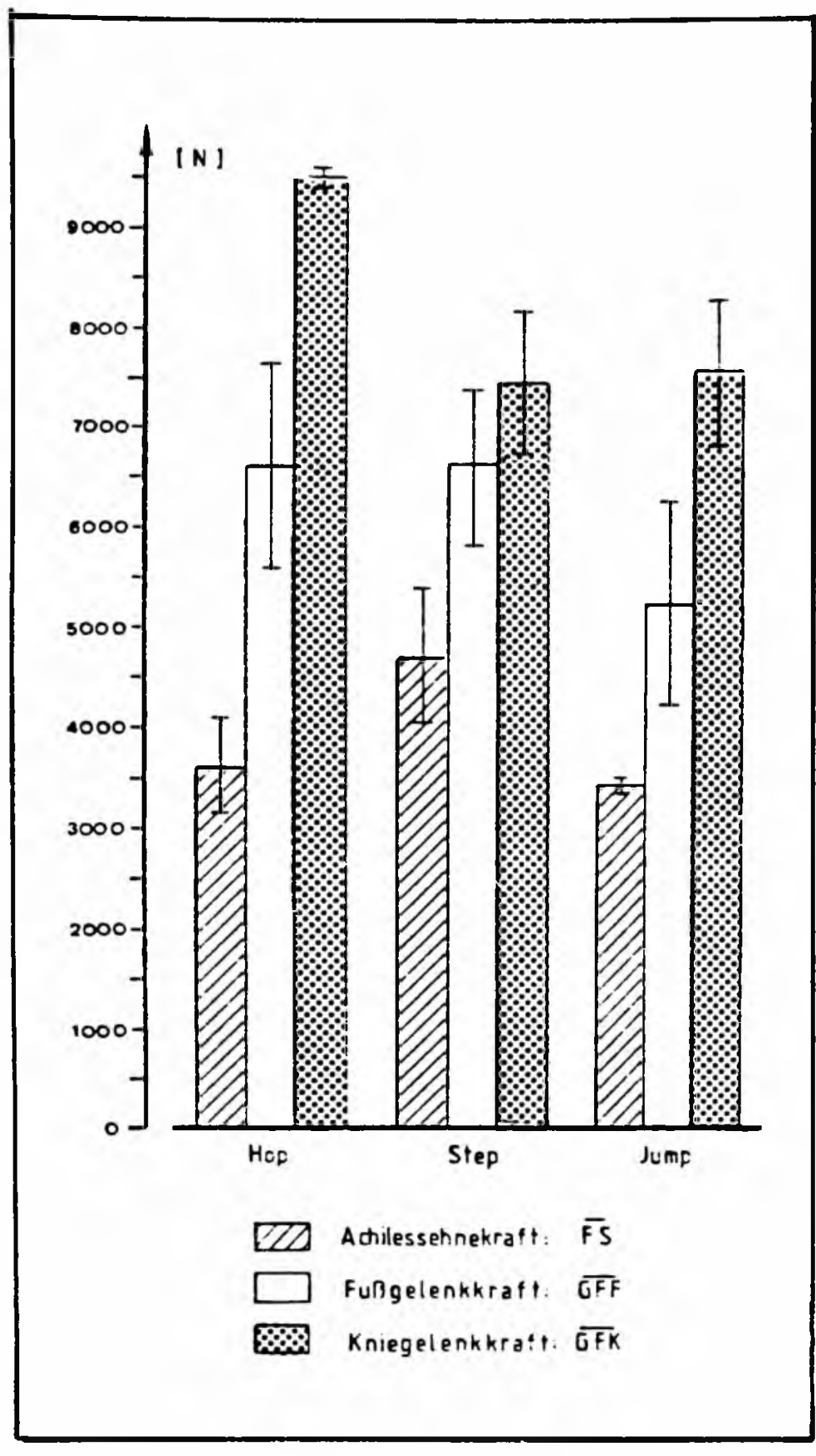

Figura 04: Valores médios da força de reação articular e força no tendão de Aquiles calculados no Plano sagital para o salto triplo. FS: Força no tendão de Aquiles, GFF: Força na articulação superior do tornozelo talo-crural, GFK: Força na articulação do joelho - femuro-tibial. ção. Entre os parâmetros que caracterizaram a sobrecarga articular calculou-se a força de reação articular (para as articulações femuro-tibial e articulação superior do tornozelo talo-crurall, assim como a força que age no tendão de Aquiles, parâmetros estes quantificados e representados na Figura 04.

Tratou o presente trabalho também da discussão dos fenômenos básicos em biomecânica, estudados no complexo da ciência do esporte, referente aos seus aspectos interdisciplinares, como por exemplo, estudo dos conceitos da biomecânica do esporte e sua evolução, métodos e procedimentos na investigação biomecânica, limites da biomecânica e análise diagnóstica dos parâmetros do rendimento esportivo e tópicos da análise da sobrecarga articular.

Desenvolveu-se, portanto, amplas discussōes metodológicas no sentido de caracterizar as áreas básicas que constituem a biomecânica do esporte bem como da relevância prática destes estudos na prática esportiva, através da análise da técnica do salto triplo que envolveu: descrição do movimento, estudos de modelos e análise de resultados, ou seja, discussão de parâmetros influenciadores no rendimento para as diferentes situações experimentais de medida utilizadas no presente trabalho.

Procurou-se ainda discutir os fatores que definem a capacitaçāo do rendimento esportivo, ou seja, aspectos de relevância no treinamento do salto, através de análises comparativas entre os parâmetros biomecânicos que caracterizam o rendimento em cada situação de medida experimen. tal. Desta forma utilizou-se a análise do salto triplo para exemplificar um procedimento de complexa investigação e assim atendermos aos propósitos básicos desta dissertação, que procurou enfocar a biomecânica do esporte como uma ciência interdisciplinar no espectro da ciência do esporte. 